\title{
The vascular phenotype in pseudoxanthoma elasticum and related disorders: contribution of a genetic disease to the understanding of vascular calcification
}

\author{
Georges Lefthériotis ${ }^{1,2}{ }^{*}$, Loukman Omarjee ${ }^{1,2}$, Olivier Le Saux ${ }^{3}$, Daniel Henrion ${ }^{2}$, Pierre Abraham ${ }^{1,2}$, \\ Fabrice Prunier ${ }^{1,4}$, Serge Willoteaux ${ }^{1,4}$ and Ludovic Martin ${ }^{1,2}$
}

1 PXE Health and Research Centre, University Hospital of Angers, Angers, France

2 L'UNAM, UMR CNRS 6214 - Inserm 1083, Medical School of Angers, Angers, France

3 John A. Burns School of Medicine, University of Hawaii, Honolulu, HI, USA

${ }^{4}$ L'UNAM, EA3860, Medical School of Angers, Angers, France

\section{Edited by:}

Olivier M. Vanakker, Ghent University Hospital, Belgium

\section{Reviewed by:}

Alexey Goltsov, University of Abertay Dundee, UK

Wei Zhang, University of Michigan USA

\section{${ }^{*}$ Correspondence:}

Georges Lefthériotis, Laboratoire $d^{\prime}$ Explorations Fonctionnelles Vasculaires, Centre Hospitalier Universitaire d'Angers, 4 rue Larrey, 49933 Angers Cedex 9, France. e-mail:geleftheriotis@chu-angers.fr
Vascular calcification is a complex and dynamic process occurring in various physiological conditions such as aging and exercise or in acquired metabolic disorders like diabetes or chronic renal insufficiency. Arterial calcifications are also observed in several genetic diseases revealing the important role of unbalanced or defective anti- or pro-calcifying factors. Pseudoxanthoma elasticum (PXE) is an inherited disease (OMIM 264800) characterized by elastic fiber fragmentation and calcification in various soft conjunctive tissues including the skin, eyes, and arterial media. The PXE disease results from mutations in the ABCC6 gene, encoding an ATP-binding cassette transporter primarily expressed in the liver, kidneys suggesting that it is a prototypic metabolic soft-tissue calcifying disease of genetic origin. The clinical expression of the PXE arterial disease is characterized by an increased risk for coronary (myocardial infarction), cerebral (aneurysm and stroke), and lower limb peripheral artery disease. However, the structural and functional changes in the arterial wall induced by PXE are still unexplained. The use of a recombinant mouse model inactivated for the Abcc6 gene is an important tool for the understanding of the PXE pathophysiology although the vascular impact in this model remains limited to date. Overlapping of the PXE phenotype with other inherited calcifying diseases could bring important informations to our comprehension of the PXE disease.

Keywords: pseudoxanthoma elasticum, calcium, vessels, cardiovascular diseases, elasticity, ankle-brachial index

\section{ARTERIAL CALCIFICATION IS AN INDEPENDENT RISK FACTOR OF CARDIOVASCULAR DISEASES}

Arterial calcification is gaining an increasing interest as an independent marker for cardiovascular $(\mathrm{CV})$ diseases in acquired metabolic diseases, such as type II diabetes (Becker et al., 2008) and chronic renal insufficiency (Goodman et al., 2000). Vascular calcification increases physiologically with age and studies from Egyptian mummies have revealed that arterial calcification is not a feature of modern life style due to the absence of risk factors such as smoking, high fat cholesterol diets encountered in these ancient civilizations (Allam et al., 2011).

Calcification of the intimal layers can complicate atherosclerotic plaques favoring the risk of rupture whereas deposit within the medial layer contributes to stiffen arterial wall leading to hypertension, cardiac hypertrophy, and heart failure (Demer and Tintut, 2008). Similarly to the bone, ectopic calcium sediment within the arterial wall is a dynamic and tightly regulated biological process involving a large number of cytokines and cellular pathways (Giachelli, 2004; Persy and D'Haese, 2009). Contrary to the bones, the artery is a tubular organ that should remain soft and flexible but resilient to the high distending blood pressure. The elastic properties of the arterial wall plays a key role in damping the cyclic pressure changes produced by the beating heart (O'Rourke et al., 2002). This dampening effect predominates within the large elastic vessels such as aorta and progressively decreases downstream as the vessel wall becomes more muscular in the medium and smallsized arteries allowing a continuous flow and to protect the thin walled capillaries against high pressures. Therefore, any changes in arterial wall elasticity, i.e., the recoiling force, and distensibility, (the capacity to be distended), either physiologically with aging (so called arteriosclerosis) or in response to abnormal metabolic conditions such as type II diabetes or chronic renal insufficiency, contribute to stiffen the arterial wall. Stiffening of the arterial wall will reduce the dampening effect leading to the increase in systemic arterial pressure, mainly pulse pressure, and ultimately damage the small capillaries in end-organs such as brain, kidneys, or heart (Laurent et al., 2009).

Our understanding of the direct or indirect contribution of calcification in the vascular system remains limited due to the multifactorial mechanisms. Although both elastic lamina and medial calcification could share similar genetic determinants, whether or not calcification precedes or follows the disruption and/or the degeneration of the elastic fibers is often difficult to establish (Wang et al., 2009). The resulting elasto-calcinosis refers to a timely 
and well-balanced interaction between several local and remote factors (see review Atkinson, 2008). The mechanisms underlying calcification of the elastic fibers are multifactorial including physico-chemical conditions, inflammation and oxydative stress, metabolic dysfunction, and unbalanced promoters/inhibitors of calcification. This process can occur focally in the intimal layer and may complicate atheromatous plaques whereas it occurs more diffusely in the media.

The role of genetics in the calcification process is likely to take an important place since than $>40 \%$ of the variance of aortic and coronary calcification phenotype could be under the control of genes. The roles of genes have been deciphered in various monogenic diseases but also in the general population (O'Donnell et al., 2002; Assimes et al., 2008; Rampersaud et al., 2008) and have been recently reviewed by Rutsch et al. (2011).

The pathophysiology of calcification in metabolic diseases is of a particular concern and the present review will focus mainly on pseudoxanthoma elasticum (PXE), an inherited disease displaying specific and unusual characteristics that belongs to a larger group of genetically and metabolically determined calcifying vascular diseases.

\section{PSEUDOXANTHOMA ELASTICUM: AN ENIGMATIC CALCIFYING GENETIC DISEASE}

Pseudoxanthoma elasticum is an inherited autosomal recessive multisystem disorder affecting connective tissues. Its phenotypic expression is characterized by the fragmentation and mineralization of elastic fibers in the skin termed elastorrhexis, the Bruch's membrane of the retina and the vasculature (Neldner, 1988; Hu et al., 2003; Uitto et al., 2011). Its prevalence is estimated from $1 / 25,000$ to $1 / 50,000$ and the causative mutations have been identified in the ABCC6 gene encoding a trans-membrane ATP-binding cassette transporter, subfamily C, member 6 (ABCC6/MRP6; Le Saux et al., 2000) that is primarily expressed in the liver and the kidney, but with much lower expression in other affected tissues such as skin, eyes, or arteries (Kool et al., 1999). The biological function of the ABCC6 transporter and its substrates remains totally unknown to date. The phenotype seems to result from an unknown defect originating from the liver and the kidney leading to the extracellular calcium sediment but probably intracellular (Martin et al., 2012). Several studies have demonstrated that normal tissues exposed to the serum from PXE patients or mice knockout for Abcc6 are able to calcify (Le Saux et al., 2006; Jiang et al., 2007, 2010). Therefore, PXE is considered as a prototypical metabolic calcifying disease of genetic origin (Jiang and Uitto, 2006). PXE is also characterized by its delayed onset and a variability in its phenotypic expression suggesting that a large number of co-factors contribute to its phenotype. The classical risk factors involved in arteriosclerosis, such as tobacco, hypertension, dyslipidemia, could be greatly suspected to interfere with the severity of the vascular expression of the disease, although most of the vascular complications in PXE occur later during the life ( $>40$ years) than the skin and eyes lesions, with an unexplained female preponderance (Uitto et al., 2010). The $2 / 3$ female-1/3 male ratio in PXE leads to an unusual and unexplained prevalence of arterial disease in female compared to the general population. A PXE-like phenotype has also been reported in other genetic diseases such as beta-thalassemia and sickle cell anemia (Fabbri et al., 2009), cutis laxa (Vanakker et al., 2007), generalized arterial calcification in infancy (Kalal etal., 2012), a defect in gamma-glutamyl carboxylase (Vanakker et al., 2007), familial idiopathic basal ganglia (Wang etal., 2012) and more rarely induced by pharmacological substances such as seen with $D$ penicillamine (Ratnavel and Norris, 1994). The fact that PXE phenotype could overlap with other genetic diseases suggests that these diseases share a common pathophysiology (Nitschke et al., 2012). The main phenotypical differences reported in the literature between the genetic calcifying diseases are summarized in Table 1.

A number of candidate substrates for ABCC6 have been hypothesized. The observation that PXE patients exhibit a low plasma vitamin $\mathrm{K}$ level and that anti-vitamin $\mathrm{K}$ drugs accelerate calcification in normal and in $\mathrm{Abcc6}^{-/-}$mice (Li et al., 2012) raised the hypothesis for a role of vitamin $\mathrm{K}$ in the calcification process. Vitamin $\mathrm{K}$ is a key factor for the activation of tissue calcification inhibitor factors such as matrix Gla proteins (MGPs). This hypothesis has not been confirmed due to no changes in the calcification process occurring in PXE animal models supplemented with vitamin K (Brampton et al., 2011; Fülöp et al., 2011; Gorgels et al., 2011). The implication of adenosine as a calcifying factor in PXE has also been hypothesized (Markello et al., 2011), as well as oxidative stress (Pasquali-Ronchetti et al., 2006; Zarbock et al., 2007), although the role of oxidative stress has not been evidenced by endothelial dysfunction at present in PXE.

\section{THE VASCULAR LESIONS AND HISTOLOGICAL FINDINGS IN PXE}

The elementary arterial lesions observed in PXE are characterized by mineralization of the elastic fibers of the medial layer, predominantly within the medium and small-sized musculo-elastic arteries. Abnormal elastic fibers are thought to be produced by the PXE skin fibroblasts (Quaglino et al., 2000), but could also occur with normal fibroblasts in the presence of PXE serum (Le Saux et al., 2006) or in presence of elastin degradation products (Simionescu etal., 2005). These findings suggest that PXE is a disorder of the mechanisms controlling the production of matrix constituents and that elastic fiber mineralization is caused by factors abnormally produced and entrapped within the fiber during elastin fibrogenesis (Baccarani-Contri et al., 1994). These finding called for the "elastosis hypothesis" as the primary mechanism in PXE and that calcification is secondary. A primary role for smooth muscle cells and fibroblasts in PXE is suspected as they are a source of many regulatory proteins involved in the calcification process such as alkaline phosphatase and MGP (Shanahan et al., 1999; Simionescu et al., 2005). Finally, an abnormal balance between elevated proteolysis activity with increased P-selectin (Gotting et al., 2008), matrix metallo-proteinase (MMP) 2 and 9 (Diekmann etal., 2009), suggests an abnormal remodeling of the extra cellular matrix (ECM) in PXE. Despite unknown mechanism sequence for elastosis and calcification, the nature and affected sites of calcification lead to different functional expression.

The macroscopic distribution of the calcification along the arterial tree can be mapped using standard X-ray, although 3D 
Table 1 | Comparative characteristics of the arterial phenotype in PXE and other related disorders.

\begin{tabular}{|c|c|c|c|c|c|}
\hline & $\begin{array}{l}\text { Beta-thalassemia/ } \\
\text { Sickle cell disease }\end{array}$ & PXE-like + cutis laxa & PXE & GACl & $\begin{array}{l}\text { ACDC } \\
\text { (or CALJA) }\end{array}$ \\
\hline \multicolumn{6}{|c|}{ Elementary arterial phenotype } \\
\hline Intima-media thickness & Increased & Unknown & Increased & & \\
\hline Endothelial dysfunction & Defective & Unknown & Unknown & Unknown & Unknown \\
\hline Stenosis & $\begin{array}{l}\text { Yes }(26.7 \% \text { mostly } \\
\text { cerebral) }\end{array}$ & Yes (PAD 50\%) & $\begin{array}{l}\text { Yes (mostly coronary } \\
\text { and cerebral) }\end{array}$ & $\begin{array}{l}\text { Yes (mostly coronary, } \\
\text { cerebral, and renal) }\end{array}$ & \\
\hline Dilatation/aneurysm & Sporadic & Yes (mostly cerebral) & Infrequent & & Popliteal \\
\hline $\begin{array}{l}\text { Calcification } \\
\text { Arterial malformations }\end{array}$ & Present & Present & $\begin{array}{l}\text { Present } \\
\text { gastrointestinal, eyes } \\
\text { (neovascularization) and carotids (?) }\end{array}$ & Present & Present \\
\hline Coagulation defects & Present (50\%) & Present & Secondary? & Present & Present \\
\hline Defective gene & $\mathrm{HBB} / \mathrm{HBF}$ & GGCX & ABCC6 & ENPP1 & NT5E \\
\hline
\end{tabular}

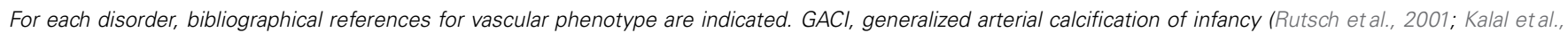

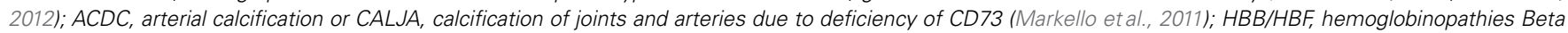

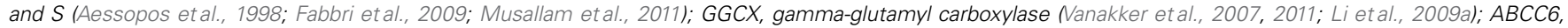

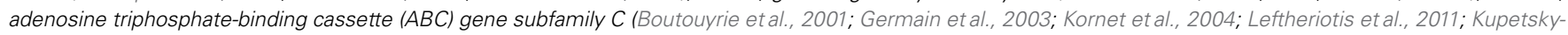

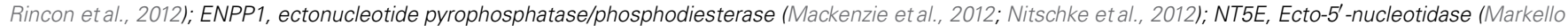
etal., 2011; St. Hilaire etal., 2011).

reconstruction using helicoidal X-rays scans provides a more precise quantification and site identification (see Figure 1). In our experience, calcification accumulates mostly within the distal superficial femoral and below-knee arteries (tibialis and pedalis), a distribution mostly observed in the arteriosclerotic process associated with aging. Skin lesions are extensively documented in PXE, as skin biopsy are routinely done for diagnosis. However, histologic findings of the PXE-related vascular lesion are sparse and obtained from rare available autopsy samples. Ultrastructural analysis from the ascending aorta, iliac arteries, and vena cava from 2 males with PXE ( 36 and 80 years old), revealed that veins and arteries were similarly damaged (Gheduzzi et al., 2003). The alterations were not distributed homogeneously along the vessels with spotty alterations of elastic fibers, and aggregates of thin strands of amorphous elastin. The von Kossa staining revealed calcium sediment within the medial layers of the arterial wall of medium (e.g., carotids)- or small (radial)-sized arteries. In carotids, calcification was found extracellularly around elastin fibers although slight increase in intracellular calcium is also observed. Elastic fibers appears fragmented and proteoglycans accumulated preferentially within the media rather than intima compared to controls (Kornet et al., 2004). Qualitative and quantitative alteration in proteoglycans metabolism have been reported with increased heparin sulfate and decreased chondroitin sulfate in patient's urine (Maccari et al., 2003).

\section{FUNCTIONAL CHANGES IN PXE ARTERY}

The functional impacts of the arterial lesions, represented by elasto-calcinosis and proteoglycans accumulation, have been examined in a limited number of studies. Most of our knowledge is derived from non-invasive structural and dynamic observations using ultrasound techniques in living subjects and have provided important data for the understanding of the arterial lesions in PXE and their clinical expression. Three functional studies involving a small number $(\approx 25)$ of PXE patients have focused on the carotid artery, an easily accessible large-sized musculo-elastic artery (Boutouyrie et al., 2001; Germain et al., 2003; Kornet etal., 2004). One of these studies has reported changes in the radial artery, a medium-sized muscular artery and the aorta, the main large-sized elastic artery of the body (Germain et al., 2003).

\section{INCREASED INTIMA MEDIA THICKNESS}

An increased carotid intima media thickness (IMT) has been reported in two human studies (Germain et al., 2003; Kornet et al., 2004) and another more recently involving mice (KupetskyRincon etal., 2012). Compared to age and gender-matched patients, these changes were more marked in older patients than in younger ones under the age of 40. An increased carotid IMT is independently associated with a higher risk for CV events which could represent a relevant argument to explain an accelerated arteriosclerosis in PXE with higher than normal CV incidents (Eigenbrodt et al., 2008). This increase in IMT was not associated with an enlargement of the lumen size and was responsible for a $19 \%$ increase in the arterial wall mass. By contrast, the radial arteries exhibited a smaller lumen with a thicker IMT, suggesting an inward remodeling (Germain et al., 2003).

The larger IMT seems to result from the higher amount of proteoglycans without proliferative change in the vascular smooth muscle cells (VSMC). Proliferation of the VSMC toward the lumen leads to arterial stenosis and occlusion, and is observed in response to an abnormal mechano-transductive signaling in elastin deficiency diseases, such as Williams-Beuren syndrome (Li et al., 1998). But this may not be the sole mechanism since a higher IMT with a progressive loss of VSMC has also been reported in Progeria (Gerhard-Herman etal., 2011). More complex 


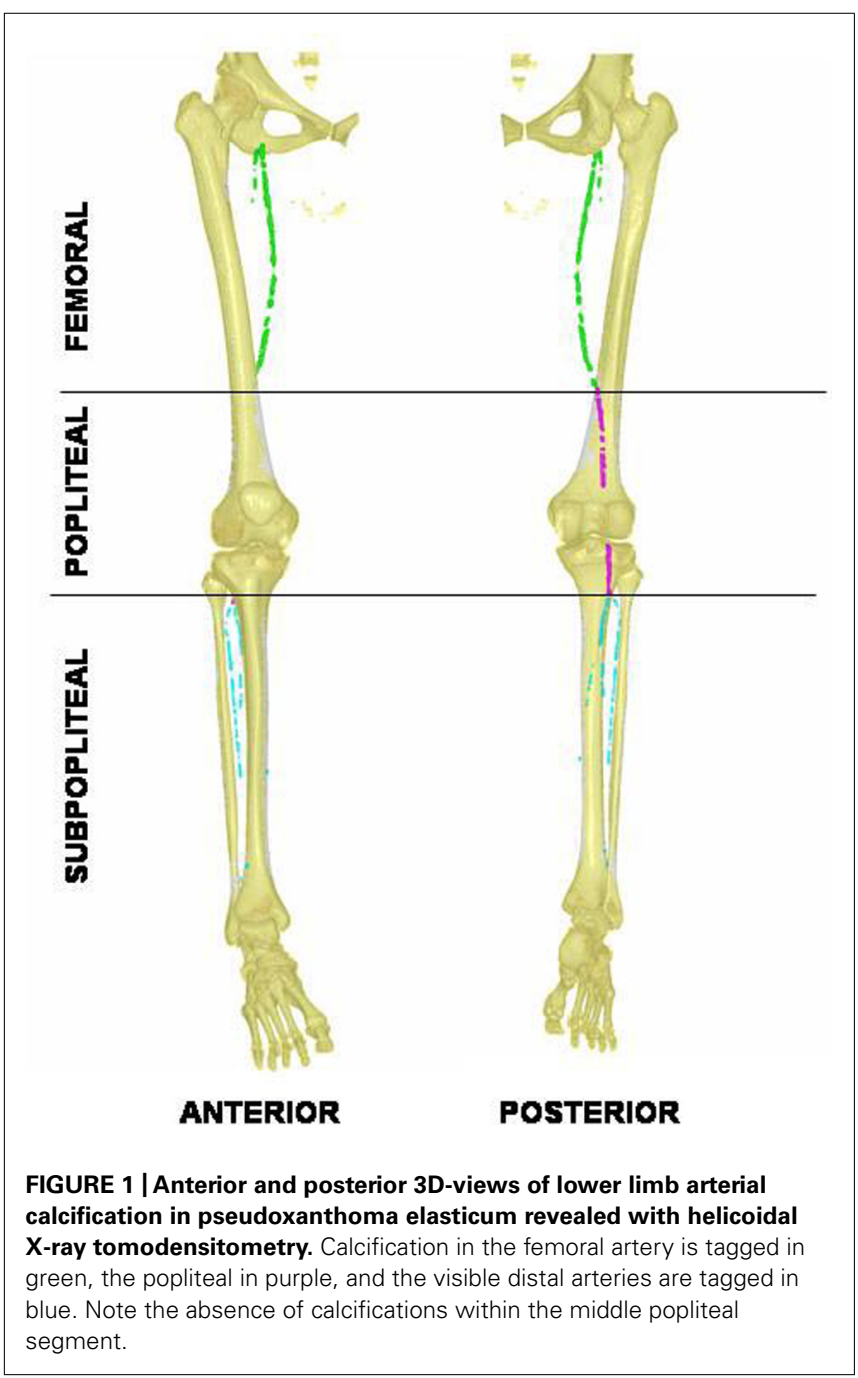

changes have also been reported with multilayered aspects in PXE coronary (Miwa et al., 2004) or mammary arteries (Sarraj et al., 1999).

Although these conclusions remain to be confirmed in larger cohorts, the arterial remodeling in PXE peripheral arteries exhibits differences from other arterial remodeling such as aging, hypertension, and atherosclerosis. This remodeling is characterized by intima-media thickening predominantly in the large and mediumsized musculo-elastic arteries (Boutouyrie et al., 1992). Aging is also defined by an outward remodeling whereas hypertension and atherosclerosis are rather characterized by an inward remodeling. This remodeling is variable along the arterial tree (Bortolotto et al., 1999; Bjarnegard and Länne, 2010) and with gender, women exhibiting a higher wall/lumen ratio than men (Green et al., 2010). The use of imaging techniques with higher spatial resolution will be very helpful to confirm and discriminate the relative changes of thickness between the intimal and medial layers, and between the different vascular beds.

Arterial wall stiffness and elasticity in PXE arteries: It is expected that both fragmentation of elastic fibers and calcification will affect the arterial elasticity of the PXE arteries.
Compared to age and sex-matched controls, the distensibility was found either unchanged (Germain et al., 2003) or higher (Kornet et al., 2004) in the large-sized artery, such as carotid, and in medium-sized arteries such as radial (Germain et al., 2003). Furthermore, in the older female patients, the elastic modulus was found unchanged in small-sized but was higher in the medium-sized artery. A lower or unchanged compressibility of the small-sized arterial wall was also reported in the ankle arteries of PXE patients (Leftheriotis et al., 2011).

Therefore, it is likely that the complex rearrangement of the extracellular matrix in PXE arterial wall resulting from the combination of elastin fragmentation associated to proteoglycans replacement, focal accumulation of calcium and activated MMP (Zarbock et al., 2010) in the media could mask a predicted arterial stiffness.

\section{CLINICAL EXPRESSION OF THE VASCULAR PXE PHENOTYPE}

The keystone clinical manifestations in PXE are represented by visual impairment due to the loss of central vision, large skin folds of esthetic concern, and CV complications (Neldner, 1988; Uitto etal., 2011). The vascular lesion in PXE takes a major place in the complications and the clinical outcome. Although, it seems that the lifespan of these patients is relatively preserved despite no clear reports on this point, the vascular impact of the disease is crucial and will be detailed in the following paragraphs.

\section{ARTERIAL HYPERTENSION}

Since the earliest reports, the presence of an arterial hypertension in PXE has been controversial with a highly variable prevalence reported in the literature ranging from $8 \%$ (Neldner, 1988 ) and up to $25 \%$ of the patients (Gotting et al., 2005). Even for the highest range, this reported prevalence remains within the overall limits of hypertension estimated to be $26.4 \%$ of the world's population (Kearney et al., 2005). In PXE, a higher than normal prevalence was likely explained on the basis of a renal artery stenosis or increased arterial stiffness resulting from the elasto-calcinosis (Goodman et al., 1963). A higher serum xylosyltransferase (XT-1), a fibrosis marker of the extracellular matrix was found in hypertensive PXE patients (Gotting et al., 2005), though this is not supported by functional data (cf paragraph above). The association between ABCC6 and angiotensin polymorphisms (T174M and M235T) was not demonstrated in hypertensive PXE compared to normals (Gotting et al., 2005). Therefore, the higher prevalence of arterial hypertension in PXE remains to be demonstrated.

\section{ANEURYSMS AND DISSECTIONS}

An abnormally dilated and/or ruptured arterial wall is the most life-threatening complication of the PXE disease. Contrary to other genetic diseases where the connective tissues are affected, as in Marfan's or Elhers-Danlos diseases, reports of aneurysm in PXE patients are sparse and almost anecdotic.

In the cerebral vasculature, the prevalence of intracranial aneurysms is difficult to estimate. A Belgian PXE cohort $(n=100)$ based on self-reported data concluded that it was an unrelated association (van den Berg etal., 2000) while the association 
between intracranial malformations, including aneurysms, and PXE may not be fortuitous (Vasseur et al., 2011).

Aneurysms in the other vascular beds such as aorta or lower limbs are very rarely reported. ABCC6 mutations were found in a minority of non-PXE patients (5/133) with abdominal aortic aneurysms (Schulz et al., 2005), but this was not statistically significantly different from healthy controls and could not be considered as a genetic risk factor for aortic aneurysms. Aortocoronary aneurysm has also been reported (Heno et al., 1998) but seems not specific to PXE as it has also been reported in other PXE-like syndromes, such as beta-thalassemia (Farmakis et al., 2004). Common genetic factors underlie medial calcification, such as ABCC6 and aneurysm development, suggesting that although medial disruption and calcification may occur in parallel, medial disruption does not strictly occur as a result of vascular calcification (Wang et al., 2009). The possibility for a higher prevalence for arterial dissection, such as the spontaneous disruption of the internal layers of an artery, common in the carotids of PXE, is still under discussion (Brandt et al., 2005), but remains anecdotic at present. Although several missense mutations (H623Q, R3190W, and R1268Q) were found in the patients with carotid dissection, these mutations were not diseasecausing as they were also detected in healthy subjects (Morcher et al., 2003).

\section{ISCHEMIC STROKE}

Beside the risk of stroke due to cerebral hemorrhage with ruptured intracranial aneurysms, the risk of ischemic stroke (IS) is another feared complication in PXE but remains difficult to establish. IS was reported in $15 \%$ of the PXE patients from a cohort of 38 patients compared to the general population $(0.3-0.5 \%$; Vanakker et al., 2008). In a cohort of 100 patients, IS was reported in seven patients with one patient having recurrent IS leading to a relative risk of 3.6 (95\% confidence interval 3.3-4.0) of ISs in patients under 65 years (van den Berg et al., 2000). Focal cerebral ischemia in PXE was predominantly caused by small-vessel occlusive disease. Atherosclerotic plaques could co-exist with PXE lesions, but results from our cohort (unpublished data) showed that carotid plaques were absent in 55/93 (59.1\%), unilateral in $17 / 93(18.3 \%)$, and bilateral in $21 / 93(22.6 \%)$ compared to age and gender-matched controls $(p=0.987)$ suggesting that it is not a primary mechanism for stroke in PXE. Transient cerebral ischemic attack could result from intermittent hemodynamic cerebral insufficiency due to intracranial arterial malformation (Vasseur et al., 2011).

\section{CARDIAC DISEASES}

Cardiac diseases in PXE are mainly represented by myocardial infarction, angina pectoris, and valvular malfunction (Neldner, 1988; Vanakker et al., 2008). Data from the largest cohorts (Neldner, 1988; Vanakker etal., 2008) have reported symptoms of myocardial origin ranging from 13 to $15 \%$ for angina pectoris but lower for infarction (1-5\%) of the patients occurring at age $<55$ years and sometimes causing death. In the coronary arterial bed, the association with a heterozygous R1141X mutation in ABCC6 and ischemic vascular events including stroke, was not demonstrated in the general population $(n=66831$ participants; Hornstrup et al., 2011), although a strong association was reported only with coronary artery disease (Koblos et al., 2010). Additionally, Abcc6 deficiency was found to increase infarct size and apoptosis in a mouse cardiac ischemia-reperfusion model, although there were no differences in cardiac calcification following ischemia/reperfusion (Mungrue et al., 2012). Abnormal coronary wall suggests that specific structural factors are likely present in these vascular beds (Miwa et al., 2004). Interestingly, the transferability of the PXE phenotype, i.e., calcification, to the arterial graft is still questioned (Sarraj et al., 1999; Iliopoulos et al., 2002; Song et al., 2004).

\section{PERIPHERAL ARTERIAL DISEASE}

Contrary to the other arterial beds, an early and severe peripheral arterial disease (PAD) described as a slowly worsening lower limb claudication is consistently and extensively reported in PXE patients without obvious $\mathrm{CV}$ risk factors. PAD is detected clinically by absence of ankle pulse, and the presence/absence of symptoms of a lower limb claudication such as a calf pain that limits or interrupts a walk. Additionally, the severity of PAD can be objectively determined by measuring the ankle-brachial systolic pressure index (ABI) which corresponds to the ratio of the systolic ankle and brachial pressures that normally ranges from 0.9 to 1.39 , and the treadmill walking distance with the help of transcutaneous PO2 (Abraham et al., 2003). The prevalence of lower limb claudication, the symptomatic expression of PAD, is very high in PXE (53\% in the Belgian cohort Vanakker et al., 2008 and 42\% in ours) (Leftheriotis et al., 2011), a proportion clearly higher than the $9 \%$ men and 5\% women with PAD reported in the general population. By contrast, the treadmill test, an objective evaluation of the arterial claudication, showed that only $56 \%$ of PXE with an $\mathrm{ABI}<0.90$ were symptomatic during the test. The discrepancy between a high proportion of PAD detected by ABI with relatively less symptoms of intermittent claudication suggests that the PAD is well compensated by an efficient collateral circulation in PXE. This tolerance to ischemia was further demonstrated in our cohort by relatively well-preserved tissue oxygenation in PXE patients during walking. Interestingly, a relatively high incidence of subclinical peripheral artery disease $(41 \%)$ was also reported in the carrier population $(n=21)$ suggesting that PAD could represent a frequent clinical manifestation, even in heterozygous patients. In addition to the presence/absence of ankle artery pulse, the ABI is a validated diagnostic tool for the detection of PAD and estimation of its severity, mainly in the asymptomatic patient (Diehm et al., 2009). PAD is also an independent marker of atherosclerosis associated with higher rates of CV diseases in the general population (Golomb etal., 2006). Calcifications in the tunica media of PXE patients are expected to increase arterial stiffness and thus decrease arterial wall compressibility (Kim et al., 2012). Although calcification predominates in the small-sized ankle arteries, the preserved arterial compressibility in these arteries remains unexplained.

\section{HEMORRHAGE}

Hemorrhages are a frequent ophthalmologic complication in PXE due to the rupture of proliferative choroidal neovascularization 
secondary to angioid streak. To a lesser extent, gastrointestinal hemorrhage have also been reported and represent a lifethreatening condition in PXE. The mechanism of hemorrhage remains unknown, but suggests sub-mucosal arterial malformations fragilized by the medial calcification with risk of rupture likely to the Bruch's membrane in the eyes. Neovessels and/or malformation could also result from defective regulatory pathways and vascular endothelial growth factor (VEGF) gene polymorphisms such as the c.-460T and the c.674C alleles that are independent risk factors for development of severe retinopathy (Zarbock et al., 2009). The genetic deficiency gamma-glutamyl carboxylase (GGCX), which is a PXE-like syndrome associated with an abnormal production of coagulation factors, are more prone to severe uncontrol bleeding (Li et al., 2009a).

\section{WHAT DOES PXE MODELS TEACH US ABOUT CARDIOVASCULAR DISEASES?}

Similar to other genetic diseases, the use of genetically engineered organisms such as mouse or zebrafish (Danio rerio) is helpful in our understanding of the PXE pathophysiology. Abcc6-/mice exhibit a low-to-mild level of medial arterial calcifications (Gorgels et al., 2005; Klement et al., 2005), although most calcification processes develop markedly in specific organs such as the vibrissae, and represents an interesting marker of peripheral calcification (Le Corre et al., 2012). Other mouse strains such as $\mathrm{C} 3 \mathrm{H} / \mathrm{HeOuJ}$ are spontaneously prone to soft connective tissues calcification, due to the defective function of Abcc6, that can be easily followed and quantified using X-rays (Le Corre et al., 2012). Finally, the zebrafish model exhibits severe abnormal development that were fully rescued by co-injection of mouse Abcc6 mRNA (Li et al., 2010). Although the mechanism of the arterial lesions in PXE remains unexplained, the fact that exteriorized tissue lesions develop remotely from the predominant sites of ABCC6 demonstrates that modifying factors are at play and limits our conclusions from these mouse models. There is now a constellation of data arguing for the concomitant role of modifying genes (Li et al., 2007; Hendig et al., 2008), polymorphisms (Schon et al., 2006) and mutations, regulatory pathways (Martin etal., 2011) as well as nutritional and environmental factors (Zarbock et al., 2007, 2009, 2010; Pisciotta et al., 2009) considerably widening the phenotypic expression and severity of the disease. Furthermore, the selective involvement of anatomical sites such as skin, eyes, arteries is usually explained by the presence of elastic fibers (with the exception of the lungs), but recent data suggests that collagen fibers could also be involved (Gorgels et al., 2012).

\section{THERAPEUTIC ISSUES IN THE PXE ARTERIAL DISEASE}

In absence of validated and specific therapeutic targets in PXE, the treatment of arteriopathy remains limited. Vitamin K was not proven as an efficient treatment, although no data are presently available in human but the lack of a consistent result in proof-of-concept studies conducted in mice are not encouraging (Gorgels etal., 2011; Jiang etal., 2012). Despite disappointing initial results from a pilot study conducted in humans (Yoo et al., 2012), attempt to reduce calcification using phosphate binder (LaRusso etal., 2009) or magnesium supplementation has recently gained renewed interest with conclusive results in Abcc6 $^{-/-}$mice (LaRusso et al., 2009; Li et al., 2009b; KupetskyRincon et al., 2012). Treatment of acute ischemic complications is sporadically reported in the literature without obvious difference compared to the general population, although reports of limb amputation in the literature have never been made to our knowledge.

Finally, the careful management of CV risk factors remains an important point since atheroma could mask pre-existing lesions. Factors that could aggravate arterial calcification should be avoided in these patients such as anti-vitamin $\mathrm{K}$ which is an oral anticoagulant drug known to favor calcification (Price et al., 1998) that can now be advantageously replaced by anti-Xa oral therapy after the hemorrhage risk/benefit balance has been properly evaluated. The question of preventive anti-platelet therapy for IS is unsolved at present. In the general population, anti-platelet treatment such as aspirin is advised for secondary prevention of IS, but the higher prevalence of upper gastrointestinal hemorrhages in PXE remains a firm contraindication for the use of aspirin as well as for anticoagulants. A major challenge for all clinical trials attempted in PXE is the need for an objective and reproducible quantification of the soft-tissue calcification. In this way, quantification of the arterial calcification could be an interesting tool complementary to skin biopsy or ultrasound imaging and ophthalmologic follow-up since the severity of cutaneous manifestations and angioid streak of PXE are likely predictive of CV involvement (Utani et al., 2010).

In conclusion, although the arterial remodeling observed in PXE shares some of the features of arteriosclerosis and other calcifying vascular diseases of metabolic origin, it is not readily comparable to atherosclerosis. This raises challenging questions on the central role of the hepato-renal axis in the soft-tissue calcifying processes and PXE represents a prototypical systemic metabolic disease of genetic origin. The severity of the disease is progressive and highly variable in which CV symptoms and PAD seems a constant finding in these patients. Furthermore, the higher than expected compressibility of the arterial wall may represent a useful marker as well as quantification of the arterial calcium load. Data from larger cohorts are awaited with more detailed phenotypic descriptions. From a clinical point of view, the absence of efficient therapy, the follow-up of these patients first requires a tight control and management of the usual CV risk factors in addition to the limitation of pro-calcifying factors. The place of other anti-calcifying drugs, such as denosumab remains unknown at present. Finally a comparative analysis of the overlapping phenotypes such as PXE, generalized arterial calcification of infancy (GACI), and other PXE-like diseases is likely to add valuable information on the elusive mechanism of calcifying genetic diseases.

\section{ACKNOWLEDGMENTS}

The authors wish to thank the French Society of Vascular Medicine, the PXE-France Patients' Association for continuing support and Jeffrey Fay for help in manuscript preparation. This work was granted by the French Society of Vascular Medicine and the "Appel d'offre interne Ca ART PXE1" from the University Hospital of Angers. 


\section{REFERENCES}

Abraham, P., Picquet, J., Vielle, B., Sigaudo-Roussel, D., PaisantThouveny, F., Enon, B., et al. (2003). Transcutaneous oxygen pressure measurements on the buttocks during exercise to detect proximal arterial ischemia: comparison with arteriography. Circulation 107, 1896 1900.

Aessopos, A., Samarkos, M., Voskaridou, E., Papaioannou, D., Tsironi, M., Kavouklis, E., et al. (1998). Arterial calcifications in beta-thalassemia. Angiology 49, 137-143.

Allam, A. H., Thompson, R. C., Wann, L. S., Miyamoto, M. I., Nur el-Din, A. e.-H., el-Maksoud, G. A., et al. (2011). Atherosclerosis in ancient Egyptian mummies: the Horus study. JACC Cardiovasc. Imaging 4, 315-327.

Assimes, T. L., Knowles, J. W., Basu, A., Iribarren, C., Southwick, A., Tang, H., et al. (2008). Susceptibility locus for clinical and subclinical coronary artery disease at chromosome 9p21 in the multi-ethnic ADVANCE study. Hum. Mol. Genet. 17, 2320-2328.

Atkinson, J. (2008). Age-related medial elastocalcinosis in arteries: mechanisms, animal models, and physiological consequences. J. Appl. Physiol. 105, 1643-1651.

Baccarani-Contri, M., Vincenzi, D., Cicchetti, F., Mori, G., and PasqualiRonchetti, I. (1994). Immunochemical identification of abnormal constituents in the dermis of pseudoxanthoma elasticum patients. Eur. J. Histochem. 38, 111-123.

Becker, A., Leber, A. W., Becker, C., von Ziegler, F., Tittus, J., Schroeder, I., et al. (2008). Predictive value of coronary calcifications for future cardiac events in asymptomatic patients with diabetes mellitus: a prospective study in 716 patients over 8 years. BMC Cardiovasc. Disord. 8:27. doi: 10.1186/1471-2261-8-27

Bjarnegard, N., and Länne, T. (2010). Arterial properties along the upper arm in humans: age-related effects and the consequence of anatomical location. J. Appl. Physiol. 108, 34-38.

Bortolotto, L. A., Hanon, O., Franconi, G., Boutouyrie, P., Legrain, S., and Girerd, X. (1999). The aging process modifies the distensibility of elastic but not muscular arteries. Hypertension 34, 889-892.

Boutouyrie, P., Germain, D. P., Tropeano, A. I., Laloux, B., Carenzi, F., Zidi, M., etal. (2001). Compressibility of the carotid artery in patients with pseudoxanthoma elasticum. Hypertension 38, 1181-1184.
Boutouyrie, P., Laurent, S., Benetos, A., Girerd, X. J., Hoeks, A. P., and Safar, M. E. (1992). Opposing effects of ageing on distal and proximal large arteries in hypertensives. J. Hypertens. Suppl. 10, S87-S91.

Brampton, C., Yamaguchi, Y., Vanakker, O., Van Laer, L., Chen, L. H., Thakore, M., et al. (2011). Vitamin K does not prevent soft tissue mineralization in a mouse model of pseudoxanthoma elasticum. Cell Cycle 10, 1810-1820.

Brandt, T., Morcher, M., and Hausser, I. (2005). Association of cervical artery dissection with connective tissue abnormalities in skin and arteries. Front. Neurol. Neurosci. 20, 16-29.

Demer, L. L., and Tintut, Y. (2008). Vascular calcification: pathobiology of a multifaceted disease. Circulation 117, 2938-2948.

Diehm, C., Allenberg, J. R., Pittrow, D., Mahn, M., Tepohl, G., Haberl, R. L., et al. (2009). Mortality and vascular morbidity in older adults with asymptomatic versus symptomatic peripheral artery disease. Circulation 120, 2053-2061.

Diekmann, U., Zarbock, R., Hendig, D., Szliska, C., Kleesiek, K., and Gotting, C. (2009). Elevated circulating levels of matrix metalloproteinases MMP-2 and MMP-9 in pseudoxanthoma elasticum patients. J. Mol. Med. (Berl.), 87, 965-970.

Eigenbrodt, M. L., Bursac, Z., Tracy, R. E., Mehta, J. L., Rose, K. M., and Couper, D. J. (2008). B-mode ultrasound common carotid artery intima-media thickness and external diameter: cross-sectional and longitudinal associations with carotid atherosclerosis in a large population sample. Cardiovasc. Ultrasound 6, 10.

Fabbri, E., Forni, G. L., Guerrini, G., and Borgna-Pignatti, C. (2009). Pseudoxanthoma-elasticum-like syndrome and thalassemia: an update. Dermatol. Online J. 15, 7 .

Farmakis, D., Vesleme, V., Papadogianni, A., Tsaftaridis, P., Kapralos, P., and Aessopos, A. (2004). Aneurysmatic dilatation of ascending aorta in a patient with beta-thalassemia and a pseudoxanthoma elasticumlike syndrome. Ann. Hematol. 83, 596-599.

Fülöp, K., Jiang, Q., Wetering, K. V. D., Pomozi, V., Szabo, P., Aranyi, T., et al. (2011). ABCC6 does not transport vitamin K3-glutathione conjugate from the liver: relevance to pathomechanisms of pseudoxanthoma elasticum. Biochem. Biophys. Res. Commun. 415, 468-471.

Gerhard-Herman, M., Smoot, L. B., Wake, N., Kieran, M. W., Kleinman, M. E., Miller, D. T., et al. (2011).
Mechanisms of premature vascular aging in children with HutchinsonGilford Progeria Syndrome. Hypertension 59, 92-97.

Germain, D. P., Boutouyrie, P., Laloux, B., and Laurent, S. (2003). Arterial remodeling and stiffness in patients with pseudoxanthoma elasticum. Arterioscler. Thromb. Vasc. Biol. 23, 836-841.

Gheduzzi, D., Sammarco, R., Quaglino, D., Bercovitch, L., Terry, S., Taylor, W., et al. (2003). Extracutaneous ultrastructural alterations in pseudoxanthoma elasticum. Ultrastruct. Pathol. 27, 375-384.

Giachelli, C. M. (2004). Vascular calcification mechanisms. J. Am. Soc Nephrol. 15, 2959-2964.

Golomb, B. A., Dang, T. T., and Criqui, M. H. (2006). Peripheral arterial disease: morbidity and mortality implications. Circulation 114, 688-699.

Goodman, R. M., Smith, E. W., Paton, D., Bergman, R. A., Siegel, C. L. Ottesen, O. E., et al. (1963). Pseudoxanthoma elasticum: a clinical and histopathological study. Medicine (Baltimore) 42, 297-334.

Goodman, W. G., Goldin, J., Kuizon, B D., Yoon, C., Gales, B., Sider, D., et al. (2000). Coronary-artery calcification in young adults with end-stage renal disease who are undergoing dialysis. N. Engl. J. Med. 342, 1478-1483.

Gorgels, T. G., Hu, X., Scheffer, G. L. van der Wal, A. C., Toonstra, J., de Jong, P. T., et al. (2005). Disruption of Abcc6 in the mouse: novel insight in the pathogenesis of pseudoxanthoma elasticum. Hum. Mol. Genet. 14, 1763-1773.

Gorgels, T. G., Teeling, P., Meeldijk, J. D. Nillesen, S. T., van der Wal, A. C., van Kuppevelt, T. H., et al. (2012). Abcc6 deficiency in the mouse leads to calcification of collagen fibers in Bruch's membrane. Exp. Eye Res. 104, 59-64. Gorgels, T. G., Waarsing, J. H., Herfs, M., Versteeg, D., Schoensiegel, F., Sato T., et al. (2011). Vitamin K supplementation increases vitamin $\mathrm{K}$ tissue levels but fails to counteract ectopic calcification in a mouse model for pseudoxanthoma elasticum. J. Mol. Med. (Berl.) 89, 1125-1135.

Gotting, C., Adam, A., Szliska, C., and Kleesiek, K. (2008). Circulating P-, Land E-selectins in pseudoxanthoma elasticum patients. Clin. Biochem. 41, 368-374.

Gotting, C., Hendig, D., Adam, A., Schon, S., Schulz, V., Szliska, C., et al. (2005). Elevated xylosyltransferase I activities in pseudoxanthoma elasticum (PXE) patients as a marker of stimulated proteoglycan biosynthesis. J. Mol. Med. (Berl.) 83, 984-992.
Green, D. J., Swart, A., Exterkate, A., Naylor, L. H., Black, M. A., Cable, N. T., etal. (2010). Impact of age, sex and exercise on brachial and popliteal artery remodelling in humans. Atherosclerosis 210, 525-530.

Hendig, D., Langmann, T., Kocken, S., Zarbock, R., Szliska, C., Schmitz, G., et al. (2008). Gene expression profiling of $\mathrm{ABC}$ transporters in dermal fibroblasts of pseudoxanthoma elasticum patients identifies new candidates involved in PXE pathogenesis. Lab. Invest. 88, 1303-1315.

Heno, P., Fourcade, L., Duc, H. N., Bonello, R., Roux, O., Van de Walle, J. P., et al. (1998). [Aorto-coronary dysplasia and pseudoxanthoma elastica]. Arch. Mal. Coeur Vaiss 91, 415-418.

Hornstrup, L. S., Tybjærg-Hansen, A., Haase, C. L., Nordestgaard, B. R. G., Sillesen, H., Grande, P., et al. (2011). Heterozygosity for R1141X in ABCC6 and risk of ischemic vascular disease/clinical perspective. Circ. Cardiovasc. Genet. 534-541.

Hu, X., Plomp, A. S., van Soest, S., Wijnholds, J., de Jong, P. T., and Bergen, A. A. (2003). Pseudoxanthoma elasticum: a clinical, histopathological, and molecular update. Surv. Ophthalmol. 48, 424-438.

Iliopoulos, J., Manganas, C., Jepson, N., and Newman, D. C. (2002). Pseudoxanthoma elasticum: is the left internal mammary artery a suitable conduit for coronary artery bypass grafting? Ann. Thorac. Surg. 73, 652-653.

Jiang, Q., and Uitto, J. (2006). Pseudoxanthoma elasticum: a metabolic disease? J. Invest. Dermatol. 126, 1440-1441.

Jiang, Q., Li, Q., Grand-Pierre, A. E., Schurgers, L. J., and Uitto, J. (2012). Administration of vitamin $\mathrm{K}$ does not counteract the ectopic mineralization of connective tissues in Abcc6 (-/-) mice, a model for pseudoxanthoma elasticum. Cell Cycle 10, 701-707.

Jiang, Q., Li, Q., and Uitto, J. (2007). Aberrant mineralization of connective tissues in a mouse model of pseudoxanthoma elasticum: systemic and local regulatory factors. J. Invest. Dermatol. 127, 1392-1402.

Jiang, Q., Oldenburg, R., Otsuru, S., Grand-Pierre, A. E., Horwitz, E. M., and Uitto, J. (2010). Parabiotic heterogenetic pairing of Abcc6-/-/Rag1-/- mice and their wild-type counterparts halts ectopic mineralization in a murine model of pseudoxanthoma elasticum. Am. J. Pathol. 176, 1855-1862.

Kalal, I. G., Seetha, D., Panda, A., Nitschke, Y., and Rutsch, F. 
(2012). Molecular diagnosis of generalized arterial calcification of infancy (GACI). J. Cardiovasc. Dis. Res. 3, 150-154.

Kearney, P. M., Whelton, M., Reynolds, K., Muntner, P., Whelton, P. K., and He, J. (2005). Global burden of hypertension: analysis of worldwide data. Lancet 365, 217-223.

Kim, H. G., Park, S. C., Lee, S. L., Shin, O. R., Yoon, S. A., Yang, C. W., et al. (2012). Arterial micro-calcification of vascular access is associated with aortic arch calcification and arterial stiffness in hemodialysis patients. Semin. Dial. doi: 10.1111/j.1525139X.2012.01113.x [Epub ahead of print].

Klement, J. F., Matsuzaki, Y., Jiang, Q. J., Terlizzi, J., Choi, H. Y., Fujimoto, N., et al. (2005). Targeted ablation of the abcc6 gene results in ectopic mineralization of connective tissues. $\mathrm{Mol}$. Cell. Biol. 25, 8299-8310.

Koblos, G., Andrikovics, H., Prohaszka, Z., Tordai, A., Varadi, A., and Aranyi, T. (2010). The R1141X lossof-function mutation of the ABCC6 gene is a strong genetic risk factor for coronary artery disease. Genet. Test. Mol. Biomarkers 14, 75-78.

Kool, M., van der Linden, M., de Haas, M., Baas, F., and Borst, P. (1999). Expression of human MRP6, a homologue of the multidrug resistance protein gene MRP1, in tissues and cancer cells. Cancer Res. 59, 175-182.

Kornet, L., Bergen, A. A., Hoeks, A. P., Cleutjens, J. P., Oostra, R. J., Daemen, M. J., et al. (2004). In patients with pseudoxanthoma elasticum a thicker and more elastic carotid artery is associated with elastin fragmentation and proteoglycans accumulation. Ultrasound Med. Biol. 30, 1041-1048.

Kupetsky-Rincon, E. A., Li, Q., and Uitto, J. (2012). Magnesium reduces carotid intima-media thickness in a mouse model of pseudoxanthoma elasticum: a novel treatment biomarker. Clin. Transl. Sci. 5, 259-264.

LaRusso, J., Li, Q., Jiang, Q., and Uitto, J. (2009). Elevated dietary magnesium prevents connective tissue mineralization in a mouse model of pseudoxanthoma elasticum (Abcc6 (-/-)). J. Invest. Dermatol. 129, 13881394.

Laurent, S., Briet, M., and Boutouyrie, P. (2009). Large and small artery crosstalk and recent morbidity-mortality trials in hypertension. Hypertension 54, 388-392.

Le Corre, Y., Le Saux, O., Froeliger, F., Libouban, H., Kauffenstein, G.,
Willoteaux, S., et al. (2012). Quantification of the calcification phenotype of Abcc6-deficient mice with microcomputed tomography. Am. J. Pathol. 180, 2208-2213.

Leftheriotis, G., Abraham, P., Le Corre, Y., Le Saux, O., Henrion, D., Ducluzeau, P. H., et al. (2011). Relationship between ankle brachial index and arterial remodeling in pseudoxanthoma elasticum. J. Vasc. Surg. 54, 1390-1394.

Le Saux, O., Bunda, S., VanWart, C. M., Douet, V., Got, L., Martin, L. et al. (2006). Serum factors from pseudoxanthoma elasticum patients alter elastic fiber formation in vitro. J. Invest. Dermatol. 126, 14971505.

Le Saux, O., Urban, Z., Tschuch, C. Csiszar, K., Bacchelli, B., Quaglino, D., et al. (2000). Mutations in a gene encoding an $\mathrm{ABC}$ transporter cause pseudoxanthoma elasticum. Nat. Genet. 25, 223-227.

Li, D. Y., Brooke, B., Davis, E. C., Mecham, R. P., Sorensen, L. K., Boak, B. B., etal. (1998). Elastin is an essential determinant of arterial morphogenesis. Nature 393, 276-280.

Li, Q., Grange, D. K., Armstrong, N. L., Whelan, A. J., Hurley, M. Y., Rishavy, M. A., et al. (2009a). Mutations in the GGCX and ABCC6 genes in a family with pseudoxanthoma elasticum-like phenotypes. J. Invest. Dermatol. 129, 553-563.

Li, Q., Larusso, J., Grand-Pierre, A E., and Uitto, J. (2009b). Magnesium carbonate-containing phosphate binder prevents connective tissue mineralization in Abcc6(-/-) mice-potential for treatment of pseudoxanthoma elasticum. Clin. Transl. Sci. 2, 398-404.

Li, Q., Guo, H., Chou, D., Harrington, D., Schurgers, L. J., Terry, S. F., et al. (2012). "Warfarin accelerates the ectopic mineralization in Abcc6-/- mice - clinical relevance to pseudoxanthoma elsaticum," in 2012 PXE Research Meeting, September 24 , Bethesda.

Li, Q., Jiang, Q., Larusso, J., Klement, J. F., Sartorelli, A. C., Belinsky, M. G., et al. (2007). Targeted ablation of Abccl or Abcc3 in Abcc6(-/-) mice does not modify the ectopic mineralization process. Exp. Dermatol. 16 853-859.

Li, Q., Sadowski, S., Frank, M., Chai, C. Varadi, A., Ho, S. Y., et al. (2010). The abcc6a gene expression is required for normal zebrafish development. J. Invest. Dermatol. 130, 2561-2568.

Maccari, F., Gheduzzi, D., and Volpi, N. (2003). Anomalous structure of urinary glycosaminoglycans in patients with pseudoxanthoma elasticum. Clin. Chem. 49, 380-388.

Mackenzie, N. C., Huesa, C., Rutsch, F., and Macrae, V. E. (2012). New insights into NPP1 function: lesson from clinical and animal studies. Bone 51, 961-968.

Markello, T. C., Pak, L. K., St Hilaire, C., Dorward, H., Ziegler, S. G., Chen, M. Y., et al. (2011). Vascular pathology of medial arterial calcifications in NT5E deficiency: implications for the role of adenosine in pseudoxanthoma elasticum. Mol. Genet. Metab. 103, 44-50.

Martin, L., Douet, V., VanWart, C. M., Heller, M. B., and Le Saux, O. (2011). A mouse model of betathalassemia shows a liver-specific down-regulation of Abcc6 expression. Am. J. Pathol. 178, 774-783.

Martin, L. J., Lau, E., Singh, H., Vergnes, L., Tarling, E. J., Mehrabian, M. et al. (2012). ABCC6 localizes to the mitochondria-associated membrane. Circ. Res. 111, 516-520.

Miwa, K., Higashikata, T., and Mabuchi, H. (2004). Intravascular ultrasound findings of coronary wall morphology in a patient with pseudoxanthoma elasticum. Heart 90, e61.

Morcher, M., Hausser, I., Brandt, T., and Grond-Ginsbach, C. (2003). Heterozygous carriers of Pseudoxanthoma elasticum were not found among patients with cervical artery dissections. J. Neurol. 250, 983-986.

Mungrue, I. N., Zhao, P., Yao, Y., Meng, H., Rau, C., Havel, J. V., et al. (2012). Abcc6 deficiency causes increased infarct size and apoptosis in a mouse cardiac ischemia-reperfusion model. Arterioscler. Thromb. Vasc. Biol. 31, 2806-2812.

Musallam, K. M., Beydoun, A., Hourani, R., Nasreddine, W., Raad, R., Koussa, S., etal. (2011). Brain magnetic resonance angiography in splenectomized adults with beta-thalassemia intermedia. Eur. J. Haematol. 87, 539-546.

Neldner, K. H. (1988). Pseudoxanthoma elasticum. Clin. Dermatol. 6, 1-159.

Nitschke, Y., Baujat, G., Botschen, U., Wittkampf, T., du Moulin, M., Stella, J., et al. (2012). Generalized arterial calcification of infancy and pseudoxanthoma elasticum can be caused by mutations in either ENPP1 or ABCC6. Am. J. Hum. Genet. 90, 25-39.

O’Donnell, C. J., Chazaro, I., Wilson, P. W., Fox, C., Hannan, M. T., Kiel, D. P., et al. (2002). Evidence for heritability of abdominal aortic calcific deposits in the Framingham Heart Study. Circulation 106, 337-341.
O’Rourke, M. F., Staessen, J. A., Vlachopoulos, C., Duprez, D., and Plante, G. E. (2002). Clinical applications of arterial stiffness; definitions and reference values. Am. J. Hypertens. 15, 426-444.

Pasquali-Ronchetti, I., GarciaFernandez, M. I., Boraldi, F., Quaglino, D., Gheduzzi, D., De Vincenzi Paolinelli, C., et al. (2006). Oxidative stress in fibroblasts from patients with pseudoxanthoma elasticum: possible role in the pathogenesis of clinical manifestations. J. Pathol. 208, 54-61.

Persy, V., and D'Haese, P. (2009). Vascular calcification and bone disease: the calcification paradox. Trends Mol. Med. 15, 405-416.

Pisciotta, L., Tarugi, P., Borrini, C., Bellocchio, A., Fresa, R., Guerra, D., et al. (2009). Pseudoxanthoma elasticum and familial hypercholesterolemia: a deleterious combination of cardiovascular risk factors. Atherosclerosis 210, 173-176.

Price, P. A., Faus, S. A., and Williamson, M. K. (1998). Warfarin causes rapid calcification of the elastic lamellae in rat arteries and heart valves. Arterioscler. Thromb. Vasc. Biol. 18, 14001407.

Quaglino, D., Boraldi, F., Barbieri, D., Croce, A., Tiozzo, R., and Pasquali Ronchetti, I. (2000). Abnormal phenotype of in vitro dermal fibroblasts from patients with Pseudoxanthoma elasticum (PXE). Biochim. Biophys. Acta 1501, 51-62.

Rampersaud, E., Bielak, L. F., Parsa, A., Shen, H., Post, W., Ryan, K. A., et al. (2008). The association of coronary artery calcification and carotid artery intima-media thickness with distinct, traditional coronary artery disease risk factors in asymptomatic adults. Am. J. Epidemiol. 168, 1016-1023.

Ratnavel, R. C., and Norris, P. G. (1994). Penicillamine-induced elastosis perforans serpiginosa treated successfully with isotretinoin. Dermatology 189, 81-83.

Rutsch, F., Nitschke, Y., and Terkeltaub, R. (2011). Genetics in arterial calcification: pieces of a puzzle and cogs in a wheel. Circ. Res. 109, 578-592.

Rutsch, F., Vaingankar, S., Johnson, K., Goldfine, I., Maddux, B., Schauerte, P., et al. (2001). PC-1 nucleoside triphosphate pyrophosphohydrolase deficiency in idiopathic infantile arterial calcification. Am. J. Pathol. 158, 543-554.

Sarraj, A., Al Homsi, M. F., and Khouqeer, F. (1999). Pseudoxanthoma elasticum of the internal mammary artery. Cardiovasc. Surg. 7, 381-384. 
Schon, S., Schulz, V., Prante, C., Hendig, D., Szliska, C., Kuhn, J., et al. (2006). Polymorphisms in the xylosyltransferase genes cause higher serum XT-I activity in patients with pseudoxanthoma elasticum (PXE) and are involved in a severe disease course. $J$. Med. Genet. 43, 745-759.

Schulz, V., Hendig, D., Schillinger, M., Exner, M., Domanovits, H., Raith, M., et al. (2005). Analysis of sequence variations in the ABCC6 gene among patients with abdominal aortic aneurysm and pseudoxanthoma elasticum. J. Vasc. Res. 42, 424-432.

Shanahan, C. M., Cary, N. R. B., Salisbury, J. R., Proudfoot, D., Weissberg, P. L., and Edmonds, M. E. (1999). Medial localization of mineralization-regulating proteins in association with Monckeberg's sclerosis: evidence for smooth muscle cell-mediated vascular calcification. Circulation 100, 2168-2176.

Simionescu, A., Philips, K., and Vyavahare, N. (2005). Elastin-derived peptides and TGF-betal induce osteogenic responses in smooth muscle cells. Biochem. Biophys. Res. Commun. 334, 524-532.

Song, H. K., Sharoni, E., Williams, B. Jr., Guyton, R. A., and Puskas, J. D. (2004). Long-term left internal mammary artery graft patency for coronary artery disease associated with pseudoxanthoma elasticum. Ann. Thorac. Surg. 78, 691-693.

St. Hilaire, C., Ziegler, S. G., Markello, T. C., Brusco, A., Groden, C., Gill, F., et al. (2011). NT5E mutations and arterial calcifications. N. Engl. J. Med. 364, 432-442.
Uitto, J., Bercovitch, L., Terry, S. F., and Terry, P. F. (2011). Pseudoxanthoma elasticum: progress in diagnostics and research towards treatment: summary of the 2010 PXE International Research Meeting. Am. J. Med. Genet. A 155A, 15171526.

Uitto, J., Li, Q., and Jiang, Q. (2010). Pseudoxanthoma elasticum: molecular genetics and putative pathomechanisms. J. Invest. Dermatol. 130 661-670.

Utani, A., Tanioka, M., Yamamoto, Y. Taki, R., Araki, E., Tamura, H., et al. (2010). Relationship between the distribution of pseudoxanthoma elasticum skin and mucous membrane lesions and cardiovascular involvement. J. Dermatol. 37, 130-136.

Vanakker, O. M., Leroy, B. P., Coucke, P. Bercovitch, L. G., Uitto, J., Viljoen, D. et al. (2008). Novel clinico-molecular insights in pseudoxanthoma elasticum provide an efficient molecular screening method and a comprehensive diagnostic flowchart. Hum. Mutat. 29, 205.

Vanakker, O. M., Leroy, B. P., Schurgers L. J., Vermeer, C., Coucke, P. J., and De Paepe, A. (2011). Atypical presentation of pseudoxanthoma elasticum with abdominal cutis laxa: evidence for a spectrum of ectopic calcification disorders? Am. J. Med. Genet. A 155A, 2855-2859.

Vanakker, O. M., Martin, L., Gheduzzi, D., Leroy, B. P., Loeys, B. L., Guerci, V. I., et al. (2007). Pseudoxanthoma elasticum-like phenotype with cutis laxa and multiple coagulation factor deficiency represents a separate genetic entity. J. Invest. Dermatol. $127,581-587$. van den Berg, J. S., Hennekam, R. C., Cruysberg, J. R., Steijlen, P. M., Swart, J., Tijmes, N., et al. (2000) Prevalence of symptomatic intracranial aneurysm and ischaemic stroke in pseudoxanthoma elasticum. Cerebrovasc. Dis. 10, 315-319.

Vasseur, M., Carsin-Nicol, B., Ebran, J. M., Willoteaux, S., Martin, L., and Leftheriotis, G. (2011). Carotid rete mirabile and pseudoxanthoma elasticum: an accidental association? Eur. J. Vasc. Endovasc. Surg. 42, 292-294.

Wang, C., Li, Y., Shi, L., Ren, J., Patti, M., Wang, T., et al. (2012). Mutations in SLC20A2 link familial idiopathic basal ganglia calcification with phosphate homeostasis. Nat. Genet. 44, 254-256.

Wang, S. S., Martin, L. J., Schadt, E. E., Meng, H., Wang, X., Zhao, W., et al. (2009). Disruption of the aortic elastic lamina and medial calcification share genetic determinants in mice. Circ. Cardiovasc. Genet. 2 573-582.

Yoo, J. Y., Blum, R. R., Singer, G. K., Stern, D. K., Emanuel, P. O., Fuchs, W., et al. (2012). A randomized controlled trial of oral phosphate binders in the treatment of pseudoxanthoma elasticum. J. Am. Acad. Dermatol. 65 341-348.

Zarbock, R., Hendig, D., Szliska, C., Kleesiek, K., and Gotting, C. (2007). Pseudoxanthoma elasticum: genetic variations in antioxidant genes are risk factors for early disease onset. Clin. Chem. 53, 1734-1740.

Zarbock, R., Hendig, D., Szliska, C., Kleesiek, K., and Gotting, C. (2009). Vascular endothelial growth factor gene polymorphisms as prognostic markers for ocular manifestations in pseudoxanthoma elasticum. Hum. Mol. Genet. 18, 33443351.

Zarbock, R., Hendig, D., Szliska, C., Kleesiek, K., and Götting, C. (2010). Analysis of MMP2 promoter polymorphisms in patients with pseudoxanthoma elasticum. Clin. Chim. Acta 411, 1487-1490.

Conflict of Interest Statement: The authors declare that the research was conducted in the absence of any commercial or financial relationships that could be construed as a potential conflict of interest.

Received: 31 October 2012; paper pending published: 23 November 2012; accepted: 04 January 2013; published online: 12 February 2013.

Citation: Lefthériotis G, Omarjee L, Le Saux O, Henrion D, Abraham P, Prunier F, Willoteaux S and Martin L (2013) The vascular phenotype in pseudoxanthoma elasticum and related disorders: contribution of a genetic disease to the understanding of vascular calcification. Front. Gene. 4:4. doi: 10.3389/fgene.2013.00004 This article was submitted to Frontiers in Systems Biology, a specialty of Frontiers in Genetics.

Copyright (c) 2013 Lefthériotis, Omarjee, Le Saux, Henrion, Abraham, Prunier, Willoteaux and Martin. This is an openaccess article distributed under the terms of the Creative Commons Attribution License, which permits use, distribution and reproduction in other forums, provided the original authors and source are credited and subject to any copyright notices concerning any third-party graphics etc. 